\title{
Fatigue in Context of Gender and Concrete Structure for Sustainable Development- A Comparable Thought
}

\author{
Indra Narayan Yadav ${ }^{*}, 1$ and Kamal Bahadur Thapa ${ }^{1}$ \\ ${ }^{1}$ Department of Civil Engineering, Pulchowk Campus, Institute of Engineering, \\ Tribhuvan University, Kathmandu, Nepal \\ *Corresponding Email: indra.yadav@pcampus.edu.np
}

\begin{abstract}
Application of smaller stress lesser than ultimate capacity at the repeated number of cycles to the concrete and Gender "sudden death" i.e. hearth attack in terms of damage is occurred called "Fatigue". Unequal Pay, Interview questions, Diminished responsibilities, Restrooms, Conversations, Glass Ceilings, Political bias, Terminations, Outdated views, Sexual Harassments, the main causes of gender fatigue in terms of compassion fatigue were compared to the general fatigue in concrete are well described in this paper from the stone age to till age, the dominant character as diligent shaker in the second world war was created the female gender fatigue such as the nuclei-propagation of microdefects, microvoids and fractal of rendered concrete in conjunction with more compliant are well discussed in comparative way. The product of service life along performance with environmental impact refers the degree of sustainability is well discussed by comparing the fatigue in terms of gender and concrete structure in different manners and hypothesis seems the much correlated results are validated by Microdefects, microvoids in concrete as Dalit, Dorry, Dahej, Daridra, Dar, Danger, Dominant, Dom, Dard, Dakait, Damai, Disadvantages Groups, Disable Group, Deaf, Disability etc. the majority of Nepali words and indicator of UN SDG's Viruses.
\end{abstract}

Keywords: Concrete, Fatigue, Gender, Hearth Attack, Nuclei-propagation, Sudden Death

\section{INTRODUCTION}

Fatigue is defined as the dominant failure characteristic of concrete structures under different cyclic loading which are the major causes for creation of damage and degradation of material property [1]. The foundation to predict abrupt material failure, fatigue strength of the plain cement concrete under serious service control was developed by author [2]. Based on the double bounding surface approach of damage mechanics, cyclic loaded prone structures such as bridges; highway pavements and dams which are subjected to uniaxial alternate tension-compression fatigue loading, a constitutive damage model was matured by $\mathrm{Lu} \mathrm{P}$. et. Al. [3] and for gradual material degradation of longitudinal modulus along progressive creep strains, as brittle cracking and nonlinear creep which are two components for model 
development of cyclic loading, a fatigue model was proposed by author [4]. Fatigue Tests on concrete cylinders for residual strengths and secant fatigue modulus with an increment of fatigue loading cycles, a damage model for the estimation of failure cycles with secondary strain rates of S-N Curves that alters the capacity for predictions of strength and stiffness degradations during entire process of fatigue life, mainly not consigned with the recent theories of continuum damage mechanics, that was accepted as a brittle solids model tools described in the research [5]. Microdefects, microvoids and fractal which are the main causes for the degradation of Young's modulus of elasticity in fatigue process was reported by Gao et.al [6]. Cyclic strain, the indicator of irreversible fatigue life, cyclic creep, and fatigue range that is higher than monotonic state strain and accumulated ultimate and plastic strains after each cycle before rupture, are dependent on the applied fatigue loading cycles of the concrete materials [7]. Thus, the mechanical behaviour of ordinary-reinforced concrete under cyclic loading is governed by microdefects like kinetics of the microstructure of the concrete materials and its life is dependent on the ranges of applied maximum stress and its ranges [8]. Nucleation, interaction and multi-microdefects growth that is the scenario of failure of concrete materials and cycles is inversely related to the applied stress. The model under such phenomenon is developed under bi-axial compression using bounding surface approach [9]. Anisotropic elastic degradation, strength reduction and increment of inelastic strain that are the main resources of the fatigue failures, a stress-based model having long computational time and large data storage even in a simple finite element analysis model was developed by author [10].

On the application of large number of loading cycles leading to sudden rupture or "sudden deadth" of the concrete materials, residual strength, elastic stiffness, fatigue loading that influences its capacity, the strain level notably greater than failure strain occurred in the monotonic loading state was widely described [11]. More comprehensive and rational extension of works [11] had developed in the form of anisotropic fatigue model for concrete materials [12] and further extension as strain space formulation of continuum damage mechanics [13], along with widely extension in order to capture the stiffness degradation, strength reduction, a functional fatigue damage model regarding reduction and softening of the concrete material was well developed [14] that had attributed through complex degradation of mechanics for steel and concrete composites in fatigue damage process [15]. Fully accountable for fatigue damage mechanisms, concrete integrity deterioration, irreversible strain accumulation, and reinforcement crack growth incorporated into the constitutive models, compatibility equilibrium equations of the Disturbed Stress Field Model (DSFM), analysis algorithm to predict the fatigue residual capacity of the structural element regarding fatigue life are described by authors [16].

Fatigue model for all kinds of concrete like ordinary, lightweight, high strength, fiber reinforced in tension-compression, torsional, bending either uniaxial or multiaxial as a complex phenomenon, cubical polynomial curve fittings taking correlation coefficients above than 0.937 has well developed by Y.-B. Chen Et. Al [17]. Logarithmic of maximum strain rates with continual loading for second phase of the concrete in frazzle was proposed by author [18] with index formula connected to concrete fatigue strain fitting curve [19] with employment of verification tools through the experimental results [20]. Growth of Microcracks, inelastic flow with small amplitude of cyclic loading, that is unable to take guarantee of endurance limit like metal was well developed by author [21] in conjunction to damage model. Based on the mechanics of composite materials, the permanent damage failure for ordinary concrete in compression fatigue loading with cycle and time dependent, concept of dual nature model was well established by author [22]. Another, Cumulative fatigue damage analysis related to accelerated pavement testing was performed by author [23] along with experimental result for validation of model 
has taken from the research investigation of author [24] that illustrates, the occurance of fatigue damage in concrete is about $20 \%$ of its fatigue life. Thus, based on this fact, theoritical model was presented for the prediction of sap of concrete materials during tension-compression, the altered fatigue loading with employment of double bounding surface approach making on assumption of strain-energy released rate for optimum construction of damage-effective tensor [25] and researched theoritical and practical damage frazzle constitutive model, dominant microstructural patterns, inelastic flow, microcracking natures, nuecli-propagation of fractal, degradation of Young's modulus of elasticity, the vital materials features for discovery of mechanical behavior of concrete under monotonic cyclic loading was well discussed by authors [26], [27], [28], [29], [30], [31], [32], [33], [34], [35], [36], [37], [38] and [39]. The locus of point on damage surface extended to failure surface for providing the strain at any cycles, a cumulative inelastic parameter for capturing the plastic strain, its accumulation to the normalized life, degradation of Young's modulus, strength reductions and permanent deformation formulation in the frazzle environment as a damage model is proposed in this paper for new concrete material fatigue prescriptions.

Gender equality-sexual equality or equality of the sexes, is the state of equal ease of access to resources and opportunities regardless of gender, including economic participation and decision-making; and the state of valuing different behaviors, aspirations and needs equally, regardless of gender. Gender equality is the goal achieved through gender neutrality help in achieving the goal. Gender equality is strongly tied to women's rights, and often requires policy changes. As of 2017, the global movement for gender equality has not incorporated the proposition of genders besides women and men, or gender identities outside of the gender binary. UNICEF says gender equality "means that women and men, and girls and boys, enjoy the same rights, resources, opportunities and protections. It does not require that girls and boys, or women and men, be the same, or that they be treated exactly alike.

Application of smaller stress lesser than ultimate capacity at the repeated number of cycles to the concrete and Gender "sudden death" i.e. hearth attack in terms of damage is occurred called "Fatigue". Unequal Pay, Interview questions, Diminished responsibilities, Restrooms, Conversations, Glass Ceilings, Political bias, Terminations, Outdated views, Sexual Harassments, the main causes of gender fatigue in terms of compassion fatigue were compared to the general fatigue in concrete are well described in this paper from the stone age to till age, the dominant character as diligent shaker in the second world war was created the female gender fatigue such as the nuclei-propagation of microdefects, microvoids and fractal of rendered concrete in conjunction with more compliant are well discussed in comparative way. The product of service life along performance with environmental impact refers the degree of sustainability is well discussed by comparing the fatigue in terms of gender and concrete structure in different manners and hypothesis seems the much correlated results are validated by Microdefects, microvoids in concrete as Dalit, Dorry, Dahej, Daridra, Dar, Danger, Dominant, Dom, Dard, Dakait, Damai, Disadvantages Groups, Disable Group, Deaf, Disability etc. the majority of Nepali words and indicator of UN SDG's Viruses.

\section{INITIATION OF FATIGUE IN GENDER AND CONCRETE STRUCTURES}

Degradation of elastic moduli and stiffness of the concrete at micro level field which creates non-inverse change under cyclic stress-strain with the increment of cyclic loading, are the vital causes of the fatigue failure. 
Higher levels of stress, unwanted and distressing image of traumatic material about client's experiences, sleep disturbances and nightmares, anxiety, substance abuse, physical changes, changes in cognitive schema are the major symptoms of compassion Fatigue in Gender.

4 ways to practice self-Compassion which are illustrated as (i) consider how less is more. Reduce your intake of food that depletes your energy and leaves you feeling lethargic. (ii) Add something's joyful to your daily routine. Take one or two five -minute breaks during the course of your day to do something's that lifts your heart. (iii) Rest body and mind. Turn off the computer and TV at least 30 minutes before going to bed to let your inner thoughts quite down. (iv) Engage with God. Take a slow walk around the neighborhood. Spend time reading a single Psalm or simply sit and contemplate God's love.

\section{POSSIBLE SOLUTION OF COMPASSION FATIGUE IN GENDER}
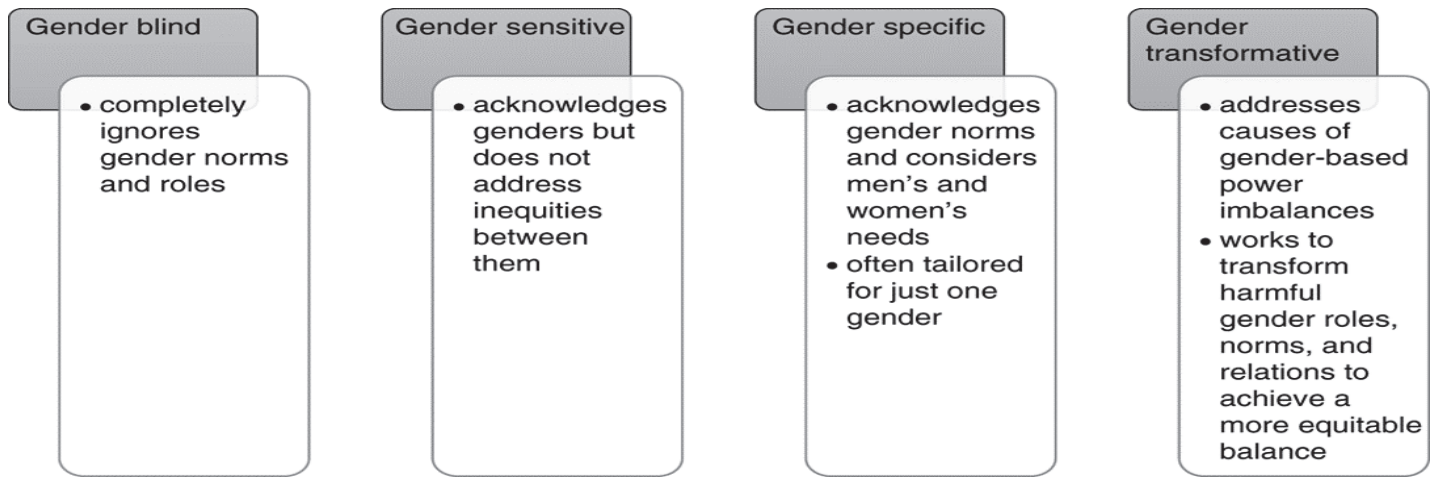

Today more than 1 billion people worldwide, the majority of whom are women, live in acceptable conditions of poverty, mostly in developing countries. Poverty has various causes. Poverty is a complex multi-dimensional problem with origins in both national and international domains. A significant trend has increased trend has increased poverty of women. Migration and consequent changes in family structures have placed additional burdens on women. These are the main scenario of Gender, Poverty and developments. Dalit, Dorry, Dahej, Daridra, Dar, Danger, Dominant, Dom, Dard, Dakait, Damai, Disadvantages Groups, Disable Group, Deaf, Disability etc the majority of domain Nepali words are the UN SDG's Viruses. We should have to develop the anti-viruses for the Gender Sustainability keeping in mind that human Cast is Past, Work is Present, Achievement is Future

\section{Gender Gap Solution:}

- Working across the Gender, like working across cultures, is a management skills.

- It requires Education, Awareness and ability to differentiate between real and unconscious biases. Large established organizations shall start to accept that gender imbalances, can be solved by

- $\quad$ Lead the charge- Leadership

- Explain why it matters-many person thought, gender imbalance is due to lack of women's choice

- $\quad$ Built Skill

- On a global scale, for achieving gender equality also requires eliminating harmful practices against women and girls, including sex trafficking, femicide, wartime sexual violence, and other oppression tactics. 
- $\quad$ UNFPA stated that, "despite many international agreements affirming their human rights, women are still much more likely than men to be poor and illiterate. They have less access to property ownership, credit, training and employment. They are far less likely than men to be politically active and far more likely to be victims of domestic violence

- As of 2017, gender equality is the fifth of seventeen sustainable development goals of the United Nations.

- $\quad$ Gender inequality is measured annually by the United Nations Development Programme's $\underline{\text { Human }}$ Development Reports

- Despite recent progress, women are still disadvantaged by their greater domestic labor commitments and impaired access to well-paid jobs; and, in extreme cases, denied the right to live.

\section{FATIGUE IN CONCRETE STRUCTURES}

- Widely used Construction Material.

- Heterogeneous: Mixture of Cement, Sand, Aggregate and Water.

- Cement paste: weakest part of aggregate interface. .

- Water and air are inside the matrix at the initial stage of production.

- Slow release of water from initial to final setting time creates microvoids at the original place of air and water - alters the chemistry of the matrix.

- Cyclic load (lower than ultimate load but higher than threshold limit) is applied to the concrete

- Separation of matrix in composition alters the ingredient from each other by creating microvoids up to fracture which is called fatigue failure.

Based on the Continuum damage mechanics approach, degraded stiffness and elastic moduli that creates microstructural damage development, a versatile concept from internal variable theory of thermodynamics with isothermal assumptions from [12] and [13], small deformations and rate independent, the Helmholtz Free Energy (HFE) per unit volume can be expressed as Equation [1]

$$
A(\varepsilon, K)=\frac{1}{2} \varepsilon: E(k): \varepsilon+A^{i}(k)
$$

Where, $\mathrm{E}, \mathrm{k}, \mathrm{A}^{\mathrm{i}}(\mathrm{k})$, : strain tensor, current fourth-order stiffness tensor, cumulative scalar damage parameter, scalar function related to microcracks surface energy, tensor contraction operation.

Following Equation [2], the constitutive relation for the concrete materials by using the Helmholtz Free energy is simply given by

$$
\sigma=\frac{\partial \mathbf{A}(\varepsilon, \mathbf{k})}{\partial \varepsilon}=\mathbf{E}(\mathbf{k}): \varepsilon
$$

The differentiation of Equation [2] with respect to Normalized life (N), the frazzle cycle, yields,

$$
\dot{\boldsymbol{\sigma}}=\mathbf{E}(\mathbf{k}): \dot{\varepsilon}+\dot{\mathbf{E}}(\mathbf{k}): \varepsilon=\dot{\boldsymbol{\sigma}}^{\mathbf{e}}+\dot{\boldsymbol{\sigma}}^{\mathbf{i}}
$$


Where in Equation [3], $\sigma, \dot{\sigma}, \dot{\varepsilon}, \mathrm{E}, \dot{\sigma}^{\mathrm{e}}, \dot{\sigma}^{\mathrm{i}}$ are the stress tensor, rate of stress tensor, rate of strain tensor with respect to cyclic number $(\mathrm{N})$, elastic stiffness tensor, elastic rate of stress tensor, rate of stress relaxation due to degradation of elastic properties of concrete materials respectively.

Damage alters the elastic properties of concrete, thus, decomposition should be added in the form of fourth-order elastic stiffness tensor which allows small deformations, the developed analytical form of Equation [4] can be written as,

$$
\mathbf{E}(\mathbf{k})=\mathbf{E}^{\mathbf{0}}+\mathbf{E}^{\mathbf{D}}
$$

Where, $\mathrm{E}^{0}, \mathrm{E}^{\mathrm{D}}$ initial undamaged stiffness tensor and overall stiffness caused by cracks and microcracks damage.

The constitutive relations for nonlinear behavior of the brittle materials describing stress-strain relation Equation [5] can be expressed as

$$
\dot{\mathbf{E}}(\mathbf{k})=-\dot{\mathbf{E}}^{\mathbf{D}}(\mathbf{k})=-\dot{\mathbf{k}} \mathbf{L}(\boldsymbol{\varepsilon})
$$

Where in Equation [5], $\mathrm{L}(\varepsilon), \mathrm{k}$ directional damage occurrence fourth order stiffness tensor, scalar measure of cumulative damage respectively.

Internal dissipation for the isothermal and small deformations, the Helmholtz Free Energy can be written as Equation [6]

$$
\mathbf{d}_{\mathbf{s}}=-\frac{\partial \mathbf{A}(\varepsilon, \mathbf{k})}{\partial \mathbf{k}} \mathbf{k} \geq \mathbf{0}
$$

Since, the Damage is assumed to be an irreversible phenomenon that leads to $\dot{\mathrm{k}} \geq 0$. Combined effect of Equation [1] and [6] in generalized form of damage surface can be written as,

$$
\theta(\varepsilon, \mathbf{k})=\frac{1}{2} \varepsilon: \mathbf{L}: \varepsilon-\frac{1}{2} \mathbf{p}^{2}(\varepsilon, \mathbf{k})=\mathbf{0}
$$

Where, in Equation (7), $\mathrm{P}(\varepsilon, \mathrm{k}), \theta(\varepsilon, \mathrm{k})$ critical strain damage function responsible for the damage growth, called critical strain as described by author [12] and [13], onset of damage in the materials that encloses the elastic domain $\theta(\varepsilon, \mathrm{k}) \geq 0$ which is unattainable for rate independent material behaviour.

For capturing the compressive mode or mode II of cracking of concrete materials, a new specific versatile model is proposed with development of $\mathrm{L}(\varepsilon)$, the response tensor, for the continuous existence and distribution of microcracks, on true line of continuum damage mechanics approach, the compressive mode or mode II is developed due to shear sliding of existing microcrack and opening of the crack slides as shown in Figure [1]. 


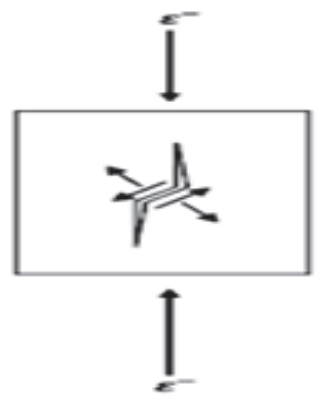

Figure 1: Fatigue crack opening in compressive mode (or mode II)

In compressive fatigue loading, the extended microcracks run in the direction that is parallel to the axis of loading resulted significant decrease in longitudinal stiffness which is due to development of tensile strains at the lateral directions and there are possibility for opening of cracks which is called "cross effect". Guided by experimental observations for concrete materials in compressive loading by authors [14], [40] and [41], the cross effect can be incorporated in above formulation by postulating the damage direction tensor $\mathrm{L}$ :

$$
\mathbf{L}=\frac{\varepsilon^{-} \otimes \varepsilon^{-}}{\varepsilon^{-}: \varepsilon^{-}}+\alpha \frac{\varepsilon^{+} \otimes \varepsilon^{+}}{\varepsilon^{+}: \varepsilon^{+}}
$$

Where, $\otimes, \varepsilon^{+}, \varepsilon^{-}$is the tensor product operator, the positive and negative cones of strain tensors, respectively. The coefficient $\alpha$ considers the extention of cross effect, which can be obtained through uniaxial compression monotonic loading test. The first part of Equation [8] refers the compressive loading directional damage, whereas the second part is the capability of the model for prediction of increment apparent Poisson's affected due to mode II damage. This means the response tensor presented in Equation [8] ensures that the prediction of damage is extended in all three principal directions of concrete during uniaxial compression test.

Guided by the experimental work of [42] and [43] and using constitutive relation for simple uniaxial compression test, the damage function can be expressed as Equation [9a], [9b], and [9c]

$$
p(\varepsilon, k)=\left(\varepsilon_{c} \sqrt{1+2 \alpha v^{2}}\right) \ln \left(\frac{E_{0}}{E_{0}-k}\right)=\varepsilon_{0} \ln \left(\frac{E_{0}}{E_{0}-k}\right)
$$

with

$$
\begin{gathered}
v=\frac{v_{0}}{1-\frac{k \alpha}{\mathrm{E}_{0}}\left(1+v_{0}\right)\left(1-2 v_{0}\right)} \\
\varepsilon_{0}=\left(\varepsilon_{c} \sqrt{1+2 \alpha v^{2}}\right)
\end{gathered}
$$

Where, $\varepsilon_{\mathrm{c}}, \mathrm{E}_{0}, \varepsilon_{0}, \mathrm{v}_{0}$, In is ultimate strain corresponding to peak stress, initial Young's Modulus of elasticity, referential strain, initial Poisson's ratio under monotonic compressive loading of the concrete material and natural logarithm respectively.

Equation [9b] implies the dependency of the Poisson's ratio $v$ at microcracking state of damage which is no longer constant. Authors [43], [44] and [45] reported that increment of monotonic loading under 
uniaxial compression attains a certain stress level at which the considerably continuous increment of Poisson's ratio started.

\section{STATISTICAL ANALYSIS}

The damage surface from Eqn [7] for the prediction of fatigue behaviour of concrete in strain space under fatigue loading at the prescribed stress level $\Delta \sigma=\sigma_{\max }-\sigma_{\min }$ remains constant; the damage surface expands successively to obtain the residual curve at failure which can be described in Figure [2].

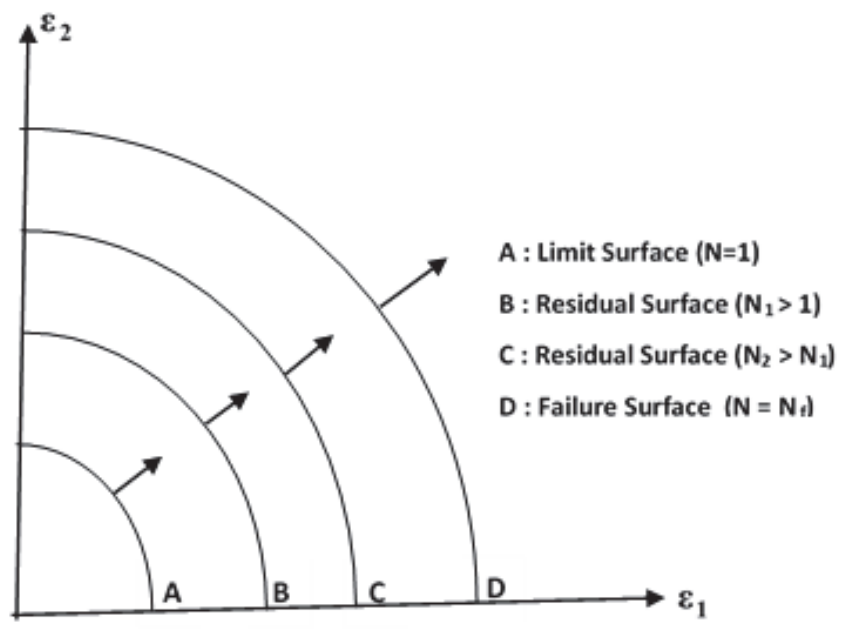

Figure 2: Residual Strain flow in biaxial compression Fatigue loading.

Stimulation of cracks and microcracks (damage) in concrete material is mainly due to increase of frazzle strain. Increment of repeated loading from maximum to minimum stress levels, the damage and residual strain increased continuously resulting final decrease in residual strength of the material which is equal to magnitude of fatigue load. After that, concrete material cannot resist any additional fatigue cycle for failure. For development of the fatigue behaviour of concrete through Equation [7], an evolutionary modified equations are predicted and proposed for fatigue damage and residual strain by adopting the parameter ' $k$ ', Equation [10] can be expressed as,

$$
\mathbf{k}=\mathbf{A} \int_{0}^{\mathbf{N}}\left(\frac{\sqrt{\varepsilon^{-}: \varepsilon^{-}}}{\varepsilon_{0}}\right)^{\mathbf{n}(1-\mathbf{r})} \mathbf{d N}
$$

Where, A, n, r, N, $\varepsilon_{0} \quad A$ and $n$ are the material constants; the stress ratio (ratio of minimum stress to maximum stress), negative cone of second order strain tensor, $\mathrm{N}$ is the number of fatigue cycles, referential strain in uniaxial compression respectively.

Researchers [8] and [9] reported that the number of cycles to the failure is directly proportional to the applied stress level duly fact that under higher value of compressive mean stress level, the formation of microcracks are inhibited due to crack closure effect. This result shows the increment of both ultimate and plastic strains, rendering concrete more flexible. The stress ratio ' $r$ ' adopted in Eqn [10] is one of the modified model for reduction of such effects. Also, it is illustrated that the increment of maximum uniaxial compression strain when reaches to the referential strain, the role of cumulative damage 
parameter starts and increases linearly with the fatigue cycle at rate of constant A called damage cycle parameter.

By differentiating Eqn [10] with respect to N, the increment of damage per cycle can be written as Eqn [11]

$$
\dot{\mathbf{k}}=\mathbf{A}\left(\frac{\sqrt{\varepsilon^{-}: \varepsilon^{-}}}{\varepsilon_{0}}\right)^{\mathbf{n}(\mathbf{1}-\mathbf{r})}
$$

Based on the stiffness degradation rule of concrete material under fatigue loading, the increment of ultimate strain and its associated inelastic strain at each cycle under monotonic loading state is obviously highlights the stiffness reduction addressed by Equation [10] and [11] clearly showing that the directly proportional relation between loading cycles and stress ratio up to accumulated plastic strain until fatigue failure. The related experimental results were also employed for such verification.

Followed by experimental observations and governing equations, the behavior of concrete under fatigue loading is captured by postulating an evolutionary proposed model's equation as described in Figure [3] to predict the failure surface in strain space of continuum damage mechanics theory with an assumption made in Eqn [9], the product of two functions and modeled stress-strain diagram drawn in Figure [4] can be expressed as Eqn [12]

$$
\mathbf{p}(\varepsilon, \mathbf{k}, \mathbf{N}, \mathbf{r})=\mathbf{G}(\mathbf{N}, \mathbf{r}) \cdot \mathbf{p}(\varepsilon, \mathbf{k})
$$

Where, $G(N, r)$ is strain softening functions, dependent on $N$, number of cycles of loading and stress ratio. Further, for the settlement of minimum value of $G(N, r)$ equals to 1 as $G_{\min }(N, r)=1$. Substituting Equation [8] and [12] into Equation [7], the damage surface in fatigue environment can be written as Equation [13]

$$
\boldsymbol{\theta}(\varepsilon, \mathbf{k}, \mathbf{N}, \mathbf{r})=\frac{1}{2} \varepsilon: \mathbf{L}: \varepsilon-\frac{1}{2} \mathbf{G}^{2}(\mathbf{N}, \mathbf{r}) \cdot \mathbf{p}^{2}(\varepsilon, \mathbf{k})=\mathbf{0}
$$

In uniaxial compression path of fatigue, the strain softening function is obtained as

$$
\mathbf{G}(\mathbf{N}, \mathbf{r})=\frac{\varepsilon}{\varepsilon_{\mathbf{c}}}
$$

Where, $\varepsilon=\varepsilon_{\max }$ in Equation (13), If G(N,r) equals to 1, the occurrence of failure of concrete becomes at one cycle at $\sigma_{\max }$ state. For maximum stress level, smaller than ultimate compressive strength of concrete material, the model functions $\mathrm{G}(\mathrm{N}, \mathrm{r})>1$. In order to obtain concrete evolutionary softening well fatigue damage model, depending upon the fatigue cycle and stress ratio, the function of $G(N, r)$ in Equation [14] is proposed as Equation [15]

$$
\mathbf{G}(\mathbf{N}, \mathbf{r})=N^{\lambda(1-r)}
$$




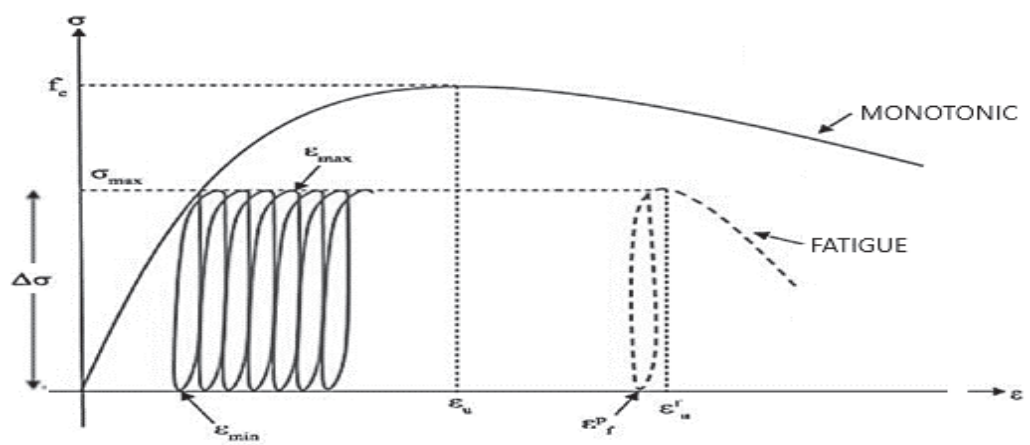

Figure 3: Idealized stress-strain of concrete material under monotonic fatigue loading.

It is unable to predict the permanent strain of concrete materials after unloading, thus the damage occurred cannot be assumed as perfectly elastic for brittle materials. A complete closure of crack cannot be achieved due to development of sizeable crack tip process with misfits on the crack surface after reversal loading leads to develop the permanent strain during cyclic loading. To capture such phenomena, stress relaxation $\dot{\sigma}$ from Eqn [3] containing two part like perfectly elastic damage and inelastic damage should be coaxial with each other can be modeled by the research of author [46] which can be adopted for fractional term of stress relaxation $\dot{\sigma}$, that can be further modified as $\mu \dot{\sigma}$, where, $\mu$ is cumulative fatigue inelastic parameter, value ranges from 0 to 1. The generalized Eqn [3] and [5] for the latest extension for inelastic damage model can be obtained as Equations [16a], [16b] and [16c]

$$
\begin{aligned}
\dot{\boldsymbol{\sigma}} & =\boldsymbol{E}(\boldsymbol{k}): \dot{\boldsymbol{\varepsilon}}+\dot{\boldsymbol{\sigma}}^{i} \\
\dot{\mathbf{E}} & =-(\mathbf{1}-\boldsymbol{\mu}) \dot{\mathbf{k} L}(\boldsymbol{\varepsilon}) \\
\dot{\boldsymbol{\sigma}} & =-\mathbf{k} \dot{\mathrm{L}}: \boldsymbol{\varepsilon}
\end{aligned}
$$

Based on these findings, the versatile cumulative fatigue inelasticity parameter can be proposed and written in this paper as Equation [17]

$$
\mu=\beta N^{-\gamma(1+r)}
$$

Where, $\beta$, and $\gamma$ are constants, $\mathrm{N}$ is the cyclic number. Substituting both the strain softening function and the damage function into the damage surface, modified form of constitutive relation, stress-strain curves can be obtained after certain number of loading cycle. The new proposed fatigue damage model presented by Eqns [10] through [17] is capable for capturing the fatigue damage behavior of concrete such as degradation of Young's Modulus of elasticity, reduction in strength, and increase in ultimate as well as plastic strain during each fatigue cycle. 
Fatigue in Context of Gender and Concrete Structure for Sustainable Development-A Comparable thought
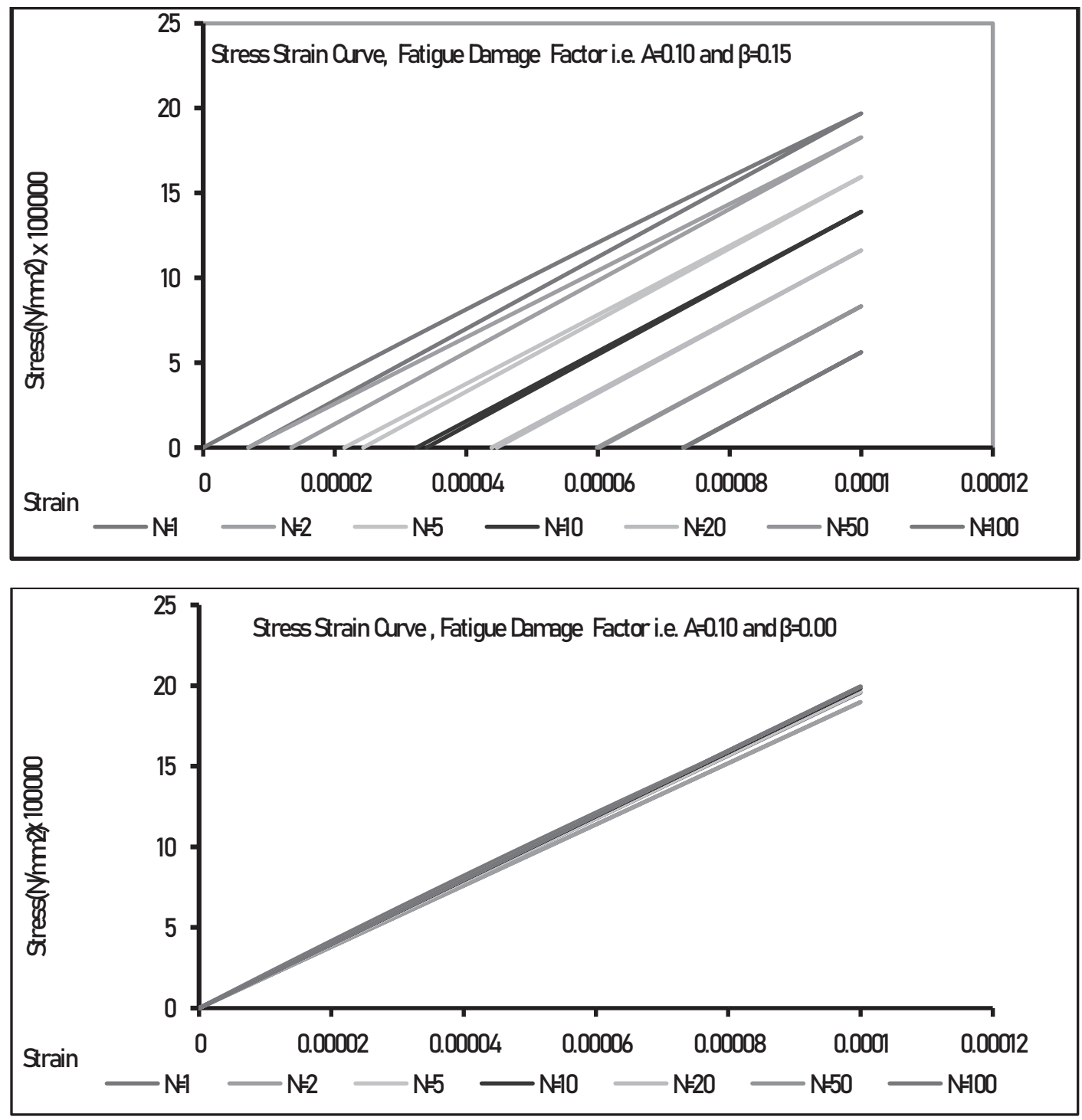

Figure 4: Concrete Stress-Strain diagram under fatigue loading. 


\section{COMPARISON TABLE OF GENDER FATIGUE AND CONCRETE FATIGUE}

\begin{tabular}{|l|l|l|}
\hline S. No & \multicolumn{1}{|c|}{ Gender fatigue } & \multicolumn{1}{|c|}{ Concrete fatigue } \\
\hline 1 & $\begin{array}{l}\text { When discrimination continues to exist as a result of } \\
\text { which organizations fail to construct the workplace } \\
\text { again and again the gender neutral, women will face } \\
\text { gender fatigue due to gender bias. The fatigue in } \\
\text { human being causes stress/heart problem leading to } \\
\text { sudden death at the age earlier than the normal life. }\end{array}$ & $\begin{array}{l}\text { If a sufficient number of fluctuating stress having maximum value } \\
\text { less than the ultimate strength is applied to concrete material, it will } \\
\text { undergo permanent damage, leading to failure due to fatigue. The } \\
\text { structures and may lead to an abrupt material failure. }\end{array}$ \\
\hline 2 & $\begin{array}{l}\text { The gender biased workplace has progressively } \\
\text { encouraged discrimination, which is harder to spot } \\
\text { and tougher to deal with. }\end{array}$ & $\begin{array}{l}\text { The cyclic loading (also called fatigue loading) in concrete } \\
\text { structures, such as bridges and pavements, creates progressive } \\
\text { permanent structural change due to the formation and nucleation of } \\
\text { microcracks and microdefects. The growth and nucleation and } \\
\text { cracks in each loading cycle has become a topic of research for } \\
\text { many researchers. }\end{array}$ \\
\hline 3 & $\begin{array}{l}\text { The gender fatigue creates health problems to to } \\
\text { women due to headache, stresses and irritations. }\end{array}$ & $\begin{array}{l}\text { The fatigue loading affects the mechanical behaviour of concrete } \\
\text { structures during its service life in terms of strength, modulus of } \\
\text { elasticity and deformation characterization. Concrete losses its } \\
\text { strength and stiffness during the process of fatigue. At fatigue } \\
\text { failure, permanent strain in concrete increases. }\end{array}$ \\
\hline 4 & $\begin{array}{l}\text { To reduce gender fatigue, we need to construct the } \\
\text { workplace as gender neutral. Organizations should } \\
\text { put the responsibility on women to overcome any } \\
\text { discrimination. }\end{array}$ & $\begin{array}{l}\text { To reduce the effect of fatigue in concrete, we need to enhance the } \\
\text { strength and ductility of concrete structures using appropriated } \\
\text { retrofitting works, such as jacketing work by FRP Composite. }\end{array}$ \\
\hline
\end{tabular}

\section{DAMAGE ACCUMULATION}

When the constant amplitude of fatigue loading is subjected to the concrete materials, then the initiation of damage can be described by Equation [1]. Whatever, on the application of variable amplitude monotonic compressive fatigue loading, the developed damage in the former stage first loading will affect the quantity of produced damage in the next stage of loading. The proposed model requires the six material parameters $(\alpha, A, n, \lambda, \beta$ and $\gamma)$, for the determination of sensitivity analysis based on the experimental results that are well described in different literatures. The formulation of fatigue constitutive relation of concrete in compression must be endorsed by commonly used structural solution codes. The prescribed maximum stress $\dot{\sigma}$ and strain levels $\dot{\varepsilon}$ for the first cycle $(\mathrm{N}=1)$ of fatigue loading is attained from Eqn [3] with updated value os $\mathrm{k}$ as $\mathrm{k}_{\mathrm{i}}=\mathrm{k}_{\mathrm{i}-1}+\mathrm{k}$ through Eqn [11] along with updated E, $v$ from Eqn [4] and [9b]. For the known stress and strain at first cycle $(\mathrm{N}=1)$ of loading, the damage surface for fatigue loading at $\mathrm{N}>1$ can be obtained from Eqn [13]. To determine the fatigue strain, damage parameter, residual strength, inelastic strain level and for fatigue failure to the next loading cycles, the entire process shall be repeated. Emergence of Model in compression fatigue loading, the theoretical stress-strain relations, strength and stiffness reductions with accumulation of plastic strains and damage are well developed in Figure [1] with damage parameter from Figure [6] and Table [1]. Stimulated concrete fatigue material parameter as $\mathrm{E}^{0}$ equals to $68869 \mathrm{MPa}$ in Equation [4], $\mathrm{v}$ equals to 0.20 in Equation [9b], $\alpha$ equals to 0.375 in Equation [9c], $\gamma$ equals to $1.11111, \beta$ equals to 0.277728 in Equation [17], $\varepsilon_{\mathrm{c}}$ equals to 0.00201 in Equation [9c], $\varepsilon$ equals to 0.00088 as stress level i.e. $0.74 \mathrm{f}_{\mathrm{c}}$ equals to $39.07 \mathrm{MPa}$, fatigue damage model as Figure [5] is developed. 


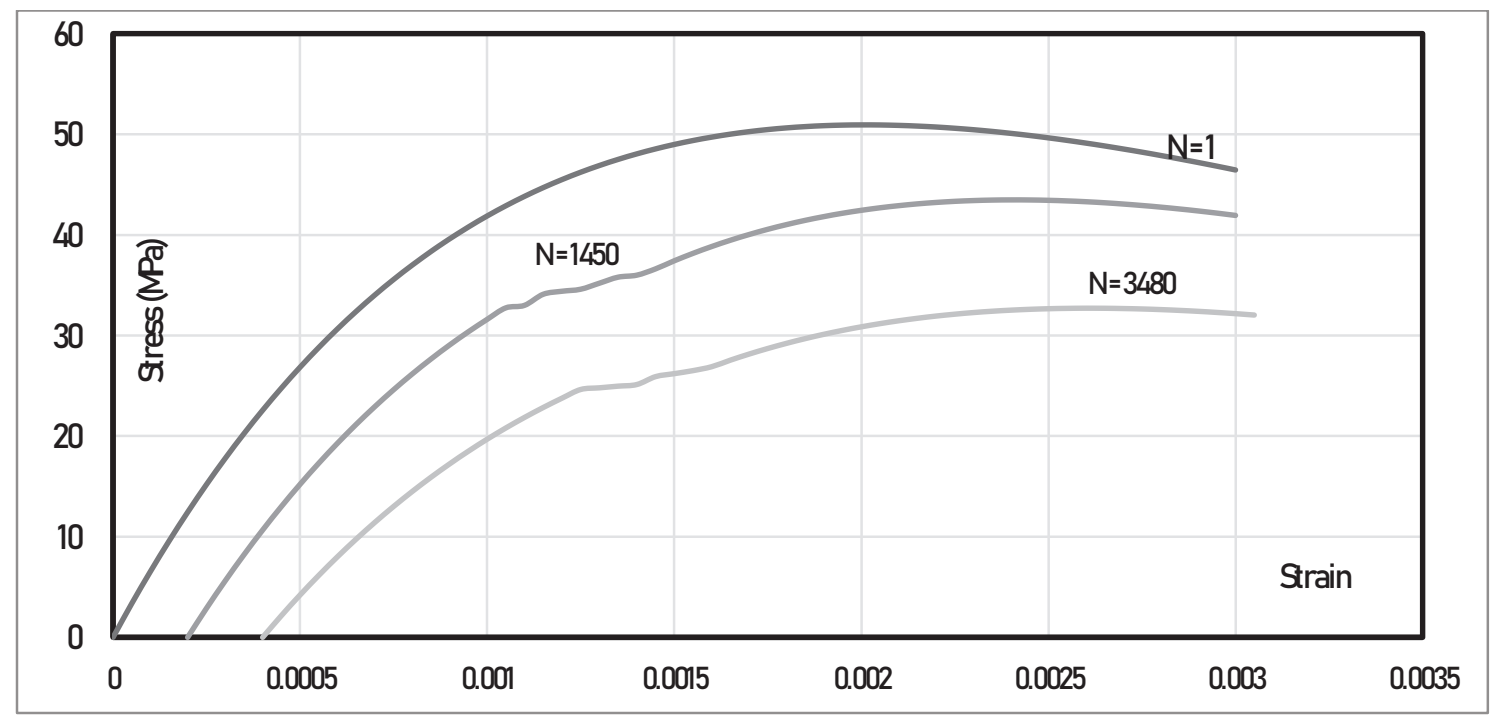

Figure 5: Concrete Stress-Strain curve in uniaxial Monotonic Fatigue loading
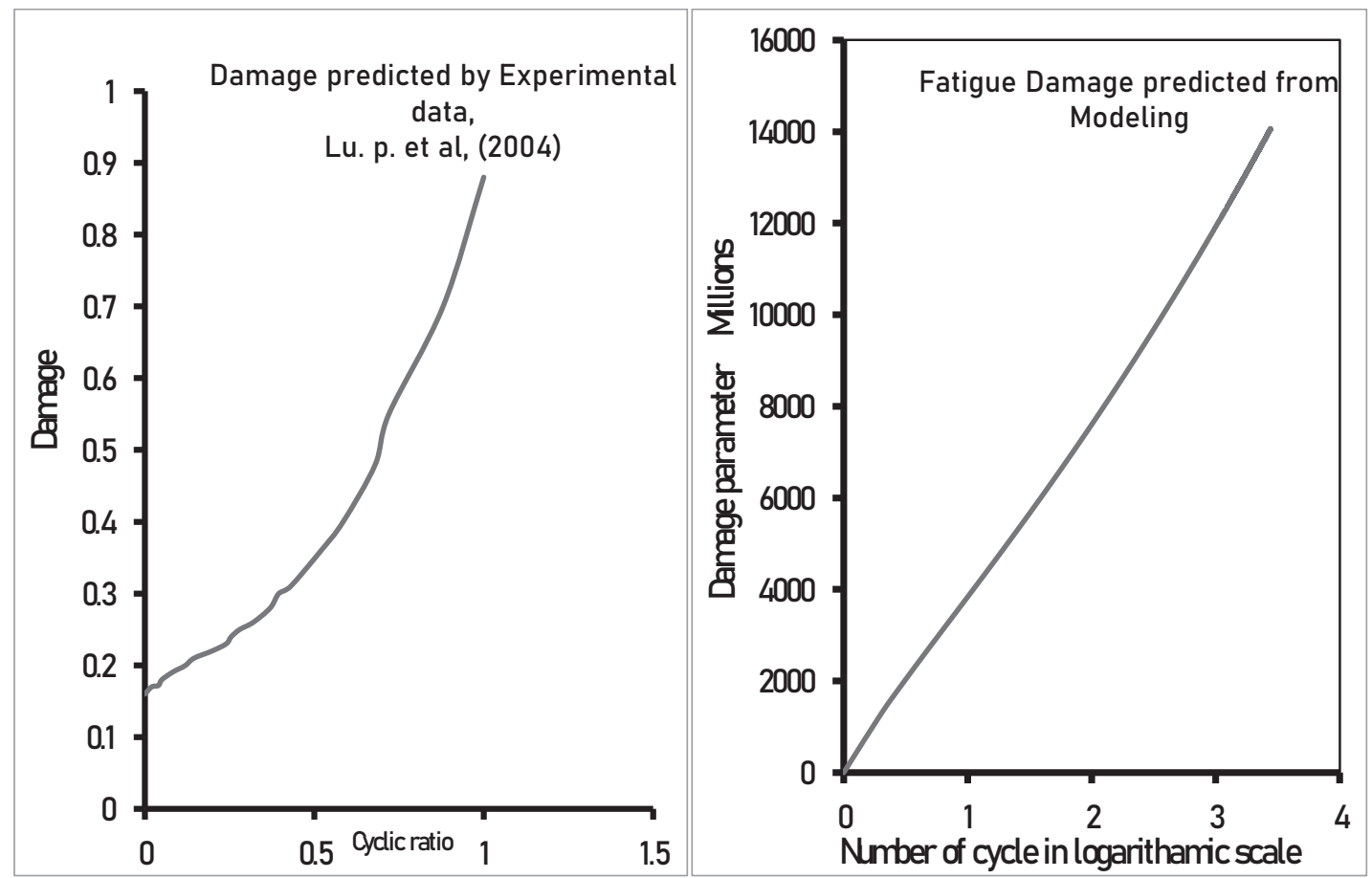

Figure 6: Damage predicted as [3] and Modeling in uniaxial Monotonic Fatigue loading 
Table 1: Damage Data by [3] due to cyclic loading in concrete Materials

\begin{tabular}{|c|c|c|c|c|c|c|c|}
\hline $\begin{array}{l}\text { Stress } \\
\text { Ratio }\end{array}$ & No. of Cycles & $\begin{array}{l}\text { Stress } \\
\text { Factor }\end{array}$ & Max. Stress & Damage & $\begin{array}{l}\text { Cyclic } \\
\text { Ratio }\end{array}$ & Damage & $\begin{array}{l}\text { Cyclic } \\
\text { Ratio }\end{array}$ \\
\hline 0.85 & 1479000 & 2.2 & 158.489319 & 0.16 & 0 & 0.23 & 0.24 \\
\hline 0.84 & 1461600 & 2.3 & 199.526231 & 0.17 & 0.02 & 0.24 & 0.255 \\
\hline 0.75 & 1305000 & 4.1 & 12589.2541 & 0.172 & 0.04 & 0.25 & 0.28 \\
\hline 0.74 & 1287600 & 4.4 & 25118.8643 & 0.18 & 0.05 & 0.26 & 0.32 \\
\hline 0.69 & 1200600 & 5.05 & 112201.845 & 0.19 & 0.08 & 0.28 & 0.37 \\
\hline 0.685 & 1191900 & 5.2 & 158489.319 & 0.195 & 0.1 & 0.48 & 0.68 \\
\hline 0.68 & 1183200 & 5.75 & 562341.325 & 0.2 & 0.12 & 0.55 & 0.72 \\
\hline 0.65 & 1131000 & 6.2 & 1584893.19 & 0.21 & 0.145 & 0.7 & 0.88 \\
\hline 0.63 & 1096200 & 6.3 & 1995262.31 & 0.22 & 0.198 & 0.88 & 1 \\
\hline
\end{tabular}

\section{VERIFICATION}

According to the experimental data of author [3], it is a good regression that the proportional constant A equals $0.10, \beta$ equals to 0 and 0.15 , changeable trend of the damage parameter in modeling and experimental is due to $100 \%$ and $85 \%$ of stress level in Figure [6]. The results show that the difference between the predicted residual fatigue life corresponding to normalized life and the experimental data are acceptable because of the big scatter of fatigue life and most points are within scatter ranges as shown in the Figure [4] and Figure [5]. Experimental fatigue life among concrete samples are subjected to the same fatigue loading are obviously very different due to bigger experimental data of author [3]. The predicted residual fatigue life by the proposed algorithm is in good agreement with the experiment, considering the bigger scatter of concrete as theory, Equations and model described above.

\section{CONCLUSION}

Application of smaller stress lesser than ultimate capacity at the repeated number of cycles to the concrete and Gender "sudden death" i.e. hearth attack in terms of damage is occurred called "Fatigue". Unequal Pay, Interview questions, Diminished responsibilities, Restrooms, Conversations, Glass Ceilings, Political bias, Terminations, Outdated views, Sexual Harassments, the main causes of gender fatigue in terms of compassion fatigue were compared to the general fatigue in concrete are well described in this paper from the stone age to till age, the dominant character as diligent shaker in the second world war was created the female gender fatigue such as the nuclei-propagation of microdefects, microvoids and fractal of rendered concrete in conjunction with more compliant are well discussed in comparative way. The product of service life along performance with environmental impact refers the degree of sustainability is well discussed by comparing the fatigue in terms of gender and concrete structure in different manners and hypothesis seems the much correlated results are validated by Microdefects, microvoids in concrete as Dalit, Dorry, Dahej, Daridra, Dar, Danger, Dominant, Dom, Dard, Dakait, Damai, Disadvantages Groups, Disable Group, Deaf, Disability etc. the majority of Nepali words and indicator of UN SDG's Viruses. 


\section{REFERENCES}

[1] S. Shiri, M. Pourgol-Mohammad, M. Yazdani, Probabilistic Assessment of Fatigue Life in Fiber Reinforced Composites, ASME International Mechanical Engineering Congress and Exposition, Montreal, Quebec, Canada, November 2014.

[2] Dyduch, K., Szerszen, M.M. and Destrebeeq, J-F (1994) 'Experimental Investigation of the Fatigue Strength of Plain Concrete under High Compression Loading", Structures and Materials, 27(173), 505-509.

[3] Lu P., Li, Q. Song, Y. (2004) "Damage Constitutive of Concrete under Uniaxial Alternate tension Compression Fatigue Loading Based on Double Bounding Surface", International journal of solids and structures, 41, 3152-3166.

[4] Maria M. SZerszen (2013) "Fatigue damage model for ordinary concrete", Open Journal of Functional Material Research, 1(2), 17-20.

[5] Benard Isojeh, Maria El-Zeghayar, and Frank j. Vecchio (2017) "Concrete damage under Fatigue Loading in Uniaxial Compression", ACI Materials journal, 114(2), 225-235.

[6] Gao, L. and Hsu, C.-T.T. (1998) "Fatigue of Concrete Under Uniaxial Compression Cyclic Loading", ACI Materials journal, 95, 578-581.

[7] Awad, M.E. (1971), "Strength and deformation characteristics of plain concrete subjected to high repeated and sustained loads. University of Illinois Experiment Station, College of Engineering, University of Illinois, Urbana-Champaign.

[8] Aas-Jakobsen, K. and Lenschow, R. (1973) "Behaviour of Reinforced Concrete Subjected to Fatigue Loading", ACI Journal Proceedings, 70, 199-206.

[9] Hsu, T.T. (1981) "Fatigue of Plain Concrete", ACI Journal Proceedings, 78, 292-305.

[10] Saboori, A., Yazdani, S., Tolliver, D. (2015) "Anisotropic Damage Mechanics Modeling of Concrete under biaxial Fatigue Loading", Open journal of Civil Engineering, 5, 8-16. http://dx.doi.org/10.4236/ojce.2015.51002

[11] Wen, C., Yazdani, S., Kim, Y.J. and Abdulrahman, M. (2012) Bounding Surface Approach to the Modeling of Anisotropic Fatigue Damage in Woven Fabric Composites. Open Journal of Composite Materials, 2, 125-132. http://dx.doi.org/10.4236/ojcm.2012.24015

[12] Thapa, K.B., Yazdani, S. (2013) "Combined damage and Plasticity Approach for Modeling Brittle Materials with Application of Concrete", International Journal of Civil and Structural Engineering, 3 (3), 513-525.

[13] Thapa, K.B., Yazdani, S. (2014) "A Strain Based Damage Mechanics Model for Plain Concrete", International Journal of Civil Engineering Research", 5 (1), 27-40.

[14] Lubliner, J. (1972) "On the thermodynamics foundations of non-linear solid mechanics", International journal of non-linear mechanics, 7 (3), 237-254.

[15] Isojeh, B., El-Zeghayar, M., and Vecchio, F.J. (2017a). "Concrete Damage under Fatigue Loading in Uniaxial Compression.” ACI Materials Journal, Vol. 114, No. 2, pp. 225-235.

[16] Isojeh, B., El-Zeghayar, M., and Vecchio, F.J. (2017b). "Simplified Constitutive Model for Fatigue Behaviour of Concrete in Compression.” Journal of Materials in Civil Engineering, DOI: 10.1061/ (ASCE)MT.1943-5533.0001863. 
[17] Y.-B. Chen, Z.-A. Lu, and D. Huang, "Fatigue defect of layer steel fiber reinforced concrete," Journal Wuhan University of Technology, Materials Science Edition, vol. 18, no. 1, pp. 65-68, 2003. [8] P. B. Cachim, J. A. Figueiras, and P. A. A. Pereira, "Fatigue behavior of fiber-reinforced concrete in compression," Cement ConcreteComposites,vol.24,no.2, pp. 211-217,2002.

[18] Y.-C .Kuangand J.-P.Ou, "Passive smart self-repairing concrete beams by using shape memory alloy wires and fibers containing adhesives," Journal of Central South University of Technology, vol.15, no.3, pp.411-417, 2008.

[19] X. W. Luo, Test Research of the Mechanics Characteristic of Recycled Aggregate Concrete under Recurrent Load, Wuhan University of Technology, School of Civil Engineering and Architecture, Wuhan,China,2006.

[20] J.-K. Kim and Y.-Y. Kim, "Experimental study of the fatigue behavior of high strength concrete," Cement and Concrete Research, vol.26, no.10, pp.1513-1523, 1996

[21] European Union - BriteEURamIII (2000) Fatigue of Normal Weight Concrete and Lightweight Concrete, Document BE 96-3942/R34.

[22] Szerszen, M.M. (2013) Fatigue damage model for ordinary concrete. Open journal of Functional Material Research (OJFMR), 1(2), 17-20

[24] Rao, S. and Roesler, J. (2004) Cumulative Fatigue Damage Analysis of Concrete Pavement using Accelerated Pavement Testing Results. In: Proceedings of the 2nd International Conference on Accelerated Pavement Testing, Minneapolis, Sep.

[25] Fardis, M.N., Alibi, B. and Tassoulas, J.L. (1983) Monotonic and Cyclic Constitutive Law for Concrete. J. Engrg, ASCE, 108EM2, 516-536.

[26] Yang, B.L., Dafalias, Y.F., Herrmann, L.R. (1985) A Bounding Surface Plasticity Model for Concrete, Proc. Paper 19539. J. Engg. Mech., ASCE 111/EM3, 359-380.

[27] Sauris, W., Ouyang, C., Fernando, V.M. (1990) Damage Model for Cyclic Loading for Concrete. J. Engg. Mech., ASCE 116(5), 1020-1035.

[28] Papa, E. (1993) A Damage Model for Concrete Subjected to Fatigue Loading. Eur.J. Mech. A/solids, 12(3), 449-440.

[29] Khan, K.R., Al-Gadhib, A.H., Baluch, M.H (1998) An Elasto-Damage Constitutive Model for High Strength Concrete. In: Proceeding of the EURO-C 1998 Conference on computational model of concrete structure at Austria, March, 133-142

[30] Cornelissen, H. A. W., and Reinhardt, H. W. (1984). "Uniaxial tensile fatigue failure of concrete under constant-amplitude and programme loading." Mag. Concr. Res., 36(129), 216-226.

[31] C. Y. Li and Y. P. Song, "Study of residual strain of concrete under fatigue loading, "Journal of Dalian University of Technology,vol.41,no.3,pp.355-358,2001.

[32] M. K. Lee and B. I. G. Barr, "An overview of the fatigue behaviour of plain and fiber reinforced concrete,” Cement \& Concrete Composites, vol. 26, no. 4, pp. 299-305, 2004.

[33] A. Alliche, "Damage model for fatigue loading of concrete," International Journal of Fatigue, vol.26, no. 9, pp. 915-921, 2004 
[34] Isojeh, B., El-Zeghayar, M., and Vecchio, F.J. (2017c). "Fatigue Behaviour of Steel Fiber Concrete in Direct Tension." Journal of Materials in Civil Engineering, DOI: 10.1061/ (ASCE) MT.1943-5533.0001949.

[35] Isojeh, M.B., and Vecchio, F.J (2016). "Parametric Damage of Concrete under High-Cycle Fatigue Loading in Compression." Proc., 9th International Conference on Fracture mechanics of Concrete and Concrete Structures. FraMCoS-9 2016; 10.21012/FC9.009.

[36] Isojeh B., El-Zeghayar M., Vecchio, F.J. "Fatigue Resistance of Steel-Fiber Reinforced Concrete Deep Beams.” ACI Structural Journal, Vol. 114, No. 5, pp. 1215-1226.

[37] Isojeh B., El-Zeghayar M., Vecchio, F.J. (2017e). "High-Cycle Fatigue Life Prediction of Reinforced Concrete Deep Beams.” Engineering Structures Journal, Vol. 150, pp. 12-24.

[38] Holmen J.O. (1982). "Fatigue of Concrete by Constant and Variable Amplitude Loading." ACI SP Vol. 75, No. 4, pp. 71-110.

[39] Herwig A. (2008). "Reinforced Concrete Bridges under Increased Railway Traffic Loads- Fatigue Behaviour and Safety Measures." Ph. D Thesis No. 4010, Ecole Polytechnique Federale de Lausanne.

[40] Karsan,I. D. \& Jirsa, J.O. (1969) " Behaviour of concrete under compressive loading ", Journal of Structures, Div. ASCE, 95(12), 2543-2563.

[41] Kupfer, H.B., Hilsdorf, H.K., and Rusch, H. (1969) " Behaviour of concrete under biaxial stresses ", Proc. ACI 66(8), 656-666.

[42] Nelson, E.L., Carrasquillo, R.L. and Fowler, D.W. (1988) "Behaviour and failure of high strength concrete subjected to biaxial cyclic compression loading", ACI Materials journal, 85, 248-253.

[43] Smith, G.M., and Young, L.E. (1955) "Ultimate theory in flexure by exponential function", Proceeding of ACI, 52 (3), 349-359.

[44] Shah, S.P. and Chandra, S. (1968) "Critical Stress, Volume Change and Microcracking of Concrete", ACI Journal Proceedings, 65 (9), Sept., 770-781.

[45] Coleman, B.D. and Gurtin, M.E. (1967) Thermodynamic with internal state variables", J. chem. Phys., 47(2), 597-613.

[46] Ortiz, M. (1985) "A Constitutive Theory for the Inelastic Behavior of Concrete", Mechanics of Materials, 4 (1), 67-93. http://dx.doi.org/10.1016/0167-6636(85)90007-9. 